\title{
Population genomics of marine fishes: next generation prospects and challenges
}

Hansen, Jakob Hemmer; Therkildsen, Nina Overgaard; Pujolar, J.M.

Published in:

Biological Bulletin

Publication date:

2014

Document Version

Publisher's PDF, also known as Version of record

Link back to DTU Orbit

Citation (APA):

Hansen, J. H., Therkildsen, N. O., \& Pujolar, J. M. (2014). Population genomics of marine fishes: next generation prospects and challenges. Biological Bulletin, 227(2), 117-132.

\section{General rights}

Copyright and moral rights for the publications made accessible in the public portal are retained by the authors and/or other copyright owners and it is a condition of accessing publications that users recognise and abide by the legal requirements associated with these rights.

- Users may download and print one copy of any publication from the public portal for the purpose of private study or research.

- You may not further distribute the material or use it for any profit-making activity or commercial gain

- You may freely distribute the URL identifying the publication in the public portal

If you believe that this document breaches copyright please contact us providing details, and we will remove access to the work immediately and investigate your claim. 


\title{
Population Genomics of Marine Fishes: Next-Generation Prospects and Challenges
}

\author{
JAKOB HEMMER-HANSEN ${ }^{1} *$, NINA OVERGAARD THERKILDSEN ${ }^{2}$ AND \\ JOSÉ MARTIN PUJOLAR ${ }^{3}$ \\ ${ }^{1}$ Section for Marine Living Resources, National Institute of Aquatic Resources, Technical University of \\ Denmark, Vejlsøvej 39, DK-8600 Silkeborg, Denmark; ${ }^{2}$ Hopkins Marine Station, Stanford University, \\ 120 Oceanview Blvd, Pacific Grove, California 93950; and ${ }^{3}$ Department of Bioscience, Aarhus \\ University, Ny Munkegade 114, DK-8000 Aarhus C, Denmark
}

\begin{abstract}
Over the past few years, technological advances have facilitated giant leaps forward in our ability to generate genome-wide molecular data, offering exciting opportunities for gaining new insights into the ecology and evolution of species where genomic information is still limited. Marine fishes are valuable organisms for advancing our understanding of evolution on historical and contemporary time scales, and here we highlight areas in which research on these species is likely to be particularly important in the near future. These include possibilities for gaining insights into processes on ecological time scales, identifying genomic signatures associated with population divergence under gene flow, and determining the genetic basis of phenotypic traits. We also consider future challenges pertaining to the implementation of genome-wide coverage through next-generation sequencing and genotyping methods in marine fishes. Complications associated with fast decay of linkage disequilibrium, as expected for species with large effective population sizes, and the possibility that adaptation is associated with both soft selective sweeps and polygenic selection, leaving complex genomic signatures in natural populations, are likely to challenge future studies. However, the combination of high genome coverage and new statistical developments offers promising solutions. Thus, the next generation of studies is likely to truly facilitate the transition from population genetics to population genomics in marine fishes. This transition will
\end{abstract}

Received 16 May 2014; accepted 29 August 2014.

* To whom correspondence should be addressed. E-mail: jhh@aqua.dtu.dk

Abbreviations: Ne, effective population size; NGS, next-generation sequencing; RAD, restriction-site associated DNA sequencing; SNP, single nucleotide polymorphism. advance our understanding of basic evolutionary processes and will offer new possibilities for conservation and management of valuable marine resources.

\section{Next-Generation Population Genomics}

The ability to achieve genome-wide coverage in genetic studies has significantly improved our understanding of demographic and evolutionary processes in natural populations of well-studied species. For instance, recent studies have unveiled demography and population history in great apes (Prado-Martinez et al., 2013), identified genes and genomic regions associated with diet and climate adaptation in humans (Hancock et al., 2010, 2011), and discovered genomic signatures associated with speciation in malaria mosquitoes (Lawniczak et al., 2010). Whole-genome resequencing data have also been used to identify genomic regions involved in repeated adaptation to freshwater environments from standing variation in marine populations of three-spined stickleback (Jones et al., 2012).

The diversity of insights in the few examples above illustrates the great promise for future studies of genomewide variation in species for which genomic resources are currently limited. There is little doubt that population-scale genome sequencing will soon be technically possible in many species (Ellegren, 2014). Even without full genome sequencing, genome-wide coverage can be approximated through a range of methods (Davey et al., 2011). Recent advances in the speed, cost, and accuracy of next-generation sequencing (NGS) technologies are shifting the paradigm of genomics to address ecological and evolutionary questions at a genome-wide scale, particularly for genomic non-model 
species (Allendorf et al., 2010; Funk et al., 2012; Narum et al., 2013).

By isolating and sequencing only a reduced subset of the genome, it is now possible to discover thousands of polymorphisms distributed genome-wide and obtain genotypes for a large number of individuals directly from the sequence data (Davey et al., 2011). The reduced genome representation can be achieved in several ways: (1) by using various steps for reducing genome complexity such as RAD (restriction-site associated DNA) sequencing and related approaches (Miller et al., 2007; Baird et al., 2008; Peterson et al., 2012; Toonen et al., 2013); (2) by targeting only the expressed parts of the genome (i.e., RNAseq, Wang et al., 2009); or (3) by isolating specific known regions of the genome through hybridization-based sequence capture or targeted amplification (Good, 2011; Grover et al., 2012), although the latter approach requires a pre-existing reference sequence from the target species or a close relative. Alternative approaches combine transcriptome and genome sequence data (e.g., Lamichaney et al,. 2012; Montes et al., 2013) or split variant discovery and genotyping in two steps, applying various sequencing methods to identify genetic variation that is subsequently genotyped on high-throughput platforms (e.g., Limborg et al., 2012; Milano et al., 2014; see also Table 1 for examples of next-generation sequencing studies in marine fishes).

In this review, we address the prospects and challenges of applying these new approaches in marine fishes, which, as outlined in the next section, represent valuable study species and systems for improving our understanding of interacting evolutionary forces.

\section{Marine Fishes as Study Systems for Understanding Evolution}

Only a few marine fish genomes have so far been sequenced (Table 2). Thus, although genomic resources are expected to increase dramatically within the next few years (Bernardi et al., 2012), most marine fishes can still be considered as non-model species with respect to availability of genomic resources. Yet these species possess a number of characteristics that make them attractive study systems with which to advance our understanding of the interacting effects of evolutionary forces in natural populations.

Fish are a paraphyletic group of vertebrates that have evolved for the past $500 \mathrm{MY}$ and comprise over 30,000 recognized species adapted to an incredible variety of conditions and habitats (Bernardi, 2013). For instance, some fish species, such as tunas (Thunnus spp.) and swordfish (Xiphias gladius), are cosmopolitan and are distributed across all oceans of the world. Other species, such as three-spined stickleback (Gasterosteus aculeatus) or eels (Anguilla spp.), can be found in highly variable habitats, including marine, brackish, and freshwater environments.
Table 1

Examples of next-generation sequencing (NGS) approaches in marine fishes*

\begin{tabular}{|c|c|}
\hline NGS approach & Species \\
\hline cDNA sequencing & $\begin{array}{l}\text { Atlantic cod (Gadus morhus; Hubert et al., } \\
\text { 2010); European hake (Merluccius } \\
\text { merluccius; Milano et al., 2011); Atlantic } \\
\text { herring (Clupea harengus; Helyar et al., } \\
\text { 2012); common sole (Solea solea; Nielsen } \\
\text { et al., 2012); Pacific herring (Clupea } \\
\text { pallasii; Roberts et al., 2012); black-faced } \\
\text { blenny (Tripterygion delaisi; Schunter et } \\
\text { al., 2014) }\end{array}$ \\
\hline $\begin{array}{l}\text { cDNA and gDNA } \\
\text { sequencing }\end{array}$ & $\begin{array}{l}\text { Atlantic herring (Clupea harengus; } \\
\text { Lamichhaney et al., 2012); European } \\
\text { anchovy (Engraulis encrasicolus; Montes } \\
\text { et al., 2013) }\end{array}$ \\
\hline $\begin{array}{l}\text { Reduced representation } \\
\text { gDNA sequencing } \\
\text { (RADseq and related } \\
\text { approaches) }\end{array}$ & $\begin{array}{l}\text { Atlantic cod (Gadus morhua; Carlsson et al., } \\
\text { 2013); Atlantic halibut (Hippoglossus } \\
\text { hippoglossus; Palaiokostas et al., 2013); } \\
\text { Atlantic herring (Clupea harengus; } \\
\text { Corander et al., 2013); European eel } \\
\text { (Anguilla anguilla; Pujolar et al., 2013a); } \\
\text { Nassau grouper (Epinephelus striatus; } \\
\text { Jackson et al., 2014); red drum (Sciaenops } \\
\text { ocellatus; Puritz et al., 2014); red snapper } \\
\text { (Lutjanus campechanus; Puritz et al., } \\
\text { 2014); silk snapper (Lutjanus vivanus; } \\
\text { Puritz et al., 2014) }\end{array}$ \\
\hline Genome resequencing & $\begin{array}{l}\text { Atlantic cod (Gadus morhua; Karlsen et al., } \\
\text { 2013) }\end{array}$ \\
\hline
\end{tabular}

* Case studies are limited to species which reproduce exclusively in marine environments. cDNA, complementary DNA, synthesized from RNA; gDNA, genomic DNA.

This diversity allows broad comparative approaches, where genomic insights can provide important information about the molecular basis of adaptation and speciation processes (e.g., Bernardi, 2013; Cutter and Payseur, 2013; Seehausen et al., 2013). Species that occupy heterogeneous environments along their distribution range experience spatially varying selective pressures that can result in local adaptation of ecologically important traits (Kawecki and Ebert, 2004). Thus, identifying regions of the genome that are involved in this adaptation is essential for understanding the mechanisms through which selection acts on natural populations (Nielsen, 2005; Stapley et al., 2010; Radwan and Babik, 2012; Bourret et al., 2013).

Many marine fishes are characterized by the production of large numbers of offspring, followed by high mortalities in early life stages, so-called type III survivorship (Wooton, 1999). Consequently, there is a large potential for selective responses at these life stages. Moreover, many marine fish species have large effective population sizes (Poulsen et al., 2006; Nielsen et al., 2009a; Therkildsen et al., 2010) and are distributed across marked environmental gradients. 
Table 2

Publicly available genome sequences in marine fishes (as of June 2014)

\begin{tabular}{|c|c|c|c|c|}
\hline Species & $\begin{array}{l}\text { Genome size } \\
(\mathrm{Mb})\end{array}$ & $\begin{array}{l}\text { Number of } \\
\text { scaffolds }\end{array}$ & $\begin{array}{l}\text { Scaffold N50 } \\
\text { length }(\mathrm{Mb})\end{array}$ & Reference \\
\hline Japanese pufferfish (Takifugu rubripes)* & 391 & 3917091 & 3910.9 & $\begin{array}{l}\text { Aparicio et al., 2002; GenBank project: } \\
\text { PRJNA166939 }\end{array}$ \\
\hline Medaka (Oryzias latipes) & 870 & 7307 & 6 & Kasahara et al., 2007 \\
\hline Atlantic cod (Gadus morhua) & 830 & 6467 & 0.7 & Star et al., 2011 \\
\hline European eel (Anguilla anguilla) & 1100 & 186281 & 0.08 & Henkel et al., 2012a \\
\hline Japanese eel (Anguilla japonica) & 1150 & 323776 & 0.05 & Henkel et al., 2012b \\
\hline Three-spined stickleback (Gasterosteus aculeatus) & 462 & 1925 & 10.8 & Jones et al., 2012 \\
\hline Coelacanth (Latimeria chalumnae) & 2860 & 22819 & 0.9 & Amemiya et al., 2013 \\
\hline Pacific bluefin tuna (Thunnus orientalis) & 800 & 16802 & 0.1 & Nakamura et al., 2013 \\
\hline Tongue sole (Cynoglossus semilaevis) & 477 & 31180 & 0.9 & Chen et al., 2014 \\
\hline
\end{tabular}

* Updated assembly data extracted from GenBank.

Therefore, natural selection pressures may be strong, and the associated genomic effects could be favored over neutral evolutionary effects from genetic drift and gene flow. On the other hand, planktonic life stages and migratory behavior in many species should facilitate the homogenizing effects of gene flow between populations. Consequently, marine fish species provide valuable systems in which to improve our understanding of the interplay between evolutionary forces in natural populations (Nielsen et al., 2009a).

The large effective population sizes in many marine fishes are often associated with high levels of standing genetic variation (Ward et al., 1994; Waples, 1998; De Woody and Avise, 2000). This characteristic indicates that high-throughput genomic approaches are likely to discover very large numbers of genomic markers in these species. Recent developments in marker discovery illustrate how next-generation approaches are becoming increasingly accessible, even for species for which genomic resources were limited until recently. In Atlantic herring (Clupea harengus), Helyar et al. (2012) developed a panel of 578 single nucleotide polymorphisms (SNPs) using next-generation transcriptome sequencing. The genomic resources in this species were soon after dramatically enhanced by the discovery of a larger panel of 440,817 SNPs after genomic sequence reads were aligned to an exome assembly built from a muscle transcriptome (Lamichhaney et al., 2012). In Atlantic cod (Gadus morhua), the discovery of about 300 genetic variants (Moen et al., 2009) was quickly followed by the publication of more than 1600 markers (Borza et al., 2010; Hubert et al., 2010). The completion of the Atlantic cod genome sequence (Star et al., 2011) and the availability of high-throughput sequencing technology have now facilitated genome resequencing and the associated discovery of more than 900,000 variants in this species (Karlsen et al., 2013). The dramatic increase in the number of markers and genome coverage in the same species over just a few years illustrates the possibilities that new technological improve- ments will soon offer in other less studied species. It also confirms the high levels of standing variation found in earlier smaller scale studies in marine fishes (Ward et al., 1994; De Woody and Avise, 2000), which have implications for population capacities for adaptive response from standing variation (see, e.g., Jones et al., 2012).

\section{Prospects of Applying Next-Generation Population Genomic Approaches in Marine Fishes}

\section{Identifying the genomic architecture underlying adaptation and population divergence with gene flow}

A classical quest in evolutionary biology has been the identification of genes and genomic regions involved in population divergence and ultimately speciation (see, e.g., Wu, 2001; Stapley et al., 2010; Feder et al., 2012; Flaxman et al., 2013). One example of local adaptation is the repeated colonization of freshwater habitats from marine populations in three-spined stickleback, identified originally at a few specific genes, such as Eda (Colosimo et al., 2005) and Pixtl (Shapiro et al., 2004). Later studies using large numbers of genetic markers and population-scale genome resequencing have identified more complex physiological processes and genomic signatures associated with parallel freshwater adaptation in the species (Hohenlohe et al., 2010; Jones et al., 2012; Deagle et al., 2013). These studies also illustrate the major advancements that can be achieved by genome-wide coverage in other species.

When divergence between populations or species occurs under gene flow, the process can be viewed as a continuum from panmixia to complete reproductive isolation as time progresses (Via, 2009; Seehausen et al., 2013). Several mechanisms could promote initial divergence at a few genomic regions while most of the genome remains homogenized through gene flow (Kondrashov and Kondrashov, 1999; Via, 2009; Feder and Nosil, 2010; Yeaman and Otto, 2011; Yeaman and Whitlock, 2011; Feder et al., 2012; see, 
a)

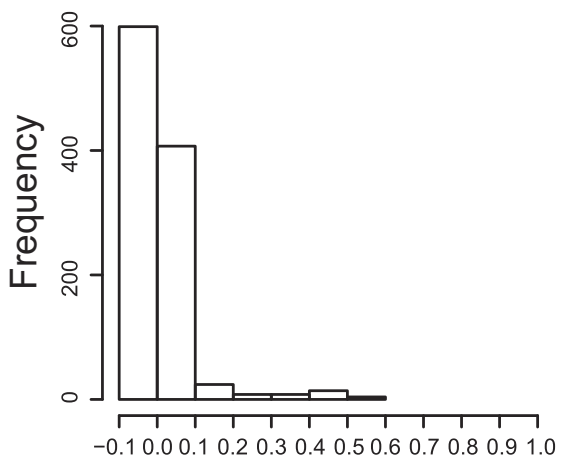

FST b)

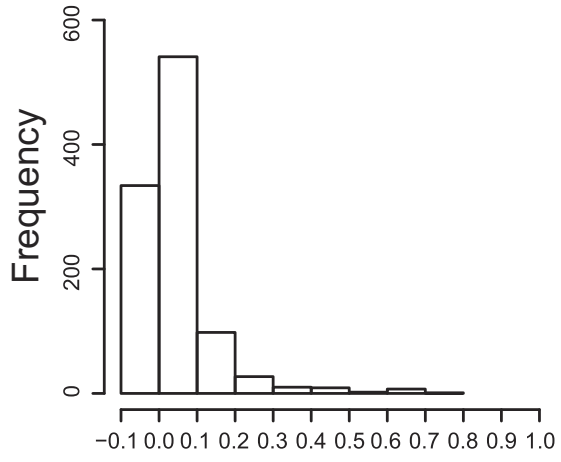

FST c)

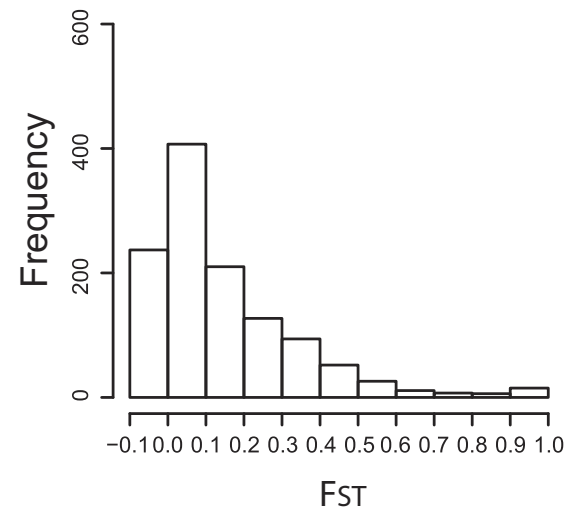

Figure 1. Distribution of single-locus estimates of pairwise population divergence (here estimated by $F_{\mathrm{ST}}$; Weir and Cockerham, 1984) in Atlantic cod. The three plots show (a) a high gene flow scenario (North Sea $v s$. coastal northern Atlantic); (b) reproductively isolated populations with recent divergence (North Sea vs. Baltic Sea); and (c) reproductively isolated populations with ancient divergence (eastern vs. western Atlantic). Data from Hemmer-Hansen et al. (2013).

however, Cruickshank and Hahn, 2014). Consequently, the distribution of divergence estimates across the genome is predicted to be L-shaped, with only a few loci showing high estimates, when population divergence is estimated at early stages of divergence. At later stages of divergence, reduced gene flow across the genome would result in a wider distribution of divergence estimates. Ideal model systems in which to identify genomic regions initially involved in population divergence are therefore characterized by significant levels of gene flow (see Via, 2009). Accordingly, the interacting effects from selection and gene flow described above make marine species excellent models for studying adaptive divergence under gene flow. In fact, some species may even provide several population pairs at different stages of the divergence process, illustrating the build-up of genome-wide reductions in gene flow as populations become reproductively isolated (see Feder et al., 2012; Hemmer-Hansen et al., 2013; and Fig. 1).

So far, few studies have examined how patterns of differentiation vary across the genome in comparisons of natural marine fish populations. European eel (Anguilla anguilla) has a unique life history involving panmictic reproduction in the Sargasso Sea (Als et al., 2011) followed by passive transport and migration of juveniles to fresh and brackish water habitats in the eastern Atlantic. A large SNP data set from RAD-sequenced immature individuals from sampling sites in the eastern Atlantic showed an overall low genomic differentiation $\left(F_{\mathrm{ST}}=0.0007\right.$; Pujolar et al., 2014a). However, a set of 754 outlier SNPs showed high genetic differentiation consistent with spatially varying selection throughout the eastern Atlantic. Sliding window analyses across genome scaffolds showed that highly divergent markers generally do not group into clusters but are spread across the genome (Fig. 2; see also Pujolar et al., 2014a). These patterns are perhaps not unexpected, as only very strong selection would be expected to result in large hitchhiking signatures after just a single generation of selection following panmixia in the Sargasso Sea.

In contrast to patterns observed in European eel, genomic clustering of some highly differentiated loci was observed in Atlantic herring (Lamichhaney et al., 2012), a species expected to have very large effective population sizes. Elevated genomic differentiation across large genomic blocks (up to $15 \mathrm{Mb}$ ) have also been reported in Atlantic cod (Bradbury et al., 2013; Hemmer-Hansen et al., 2013; Karlsen et al., 2013; Therkildsen et al., 2013a), which suggests that genomic mosaics of differentiation can be found in marine fishes. However, while these studies have applied a much larger number of genetic markers than was possible just a few years ago, they suffer from incomplete genomic resolution (Lamichhaney et al., 2012; Bradbury et al., 2013; Hemmer-Hansen et al., 2013; Therkildsen et al., 2013a) or from a restricted geographical focus (Karlsen et al., 2013). It is likely that the signals detected in Atlantic cod so far have mostly been related to structural genomic variation, to major patterns of sub-structuring on larger geographical and evolutionary time scales, or to a combination of those factors (Bradbury et al., 2013; HemmerHansen et al., 2013). Thus, structuring on finer scales is probably yet to be revealed in this species.

Importantly, despite high effective population sizes, different genomic impacts of evolutionary forces could be expected between panmictic species (e.g., European eel) and species that are genetically sub-structured into semiindependent evolutionary units (e.g., Atlantic herring and Atlantic cod; see, e.g., Charlesworth et al., 1997; Via, 2009). Although we are still quite far from a full mechanistic understanding of the genomic patterns reviewed here, it 

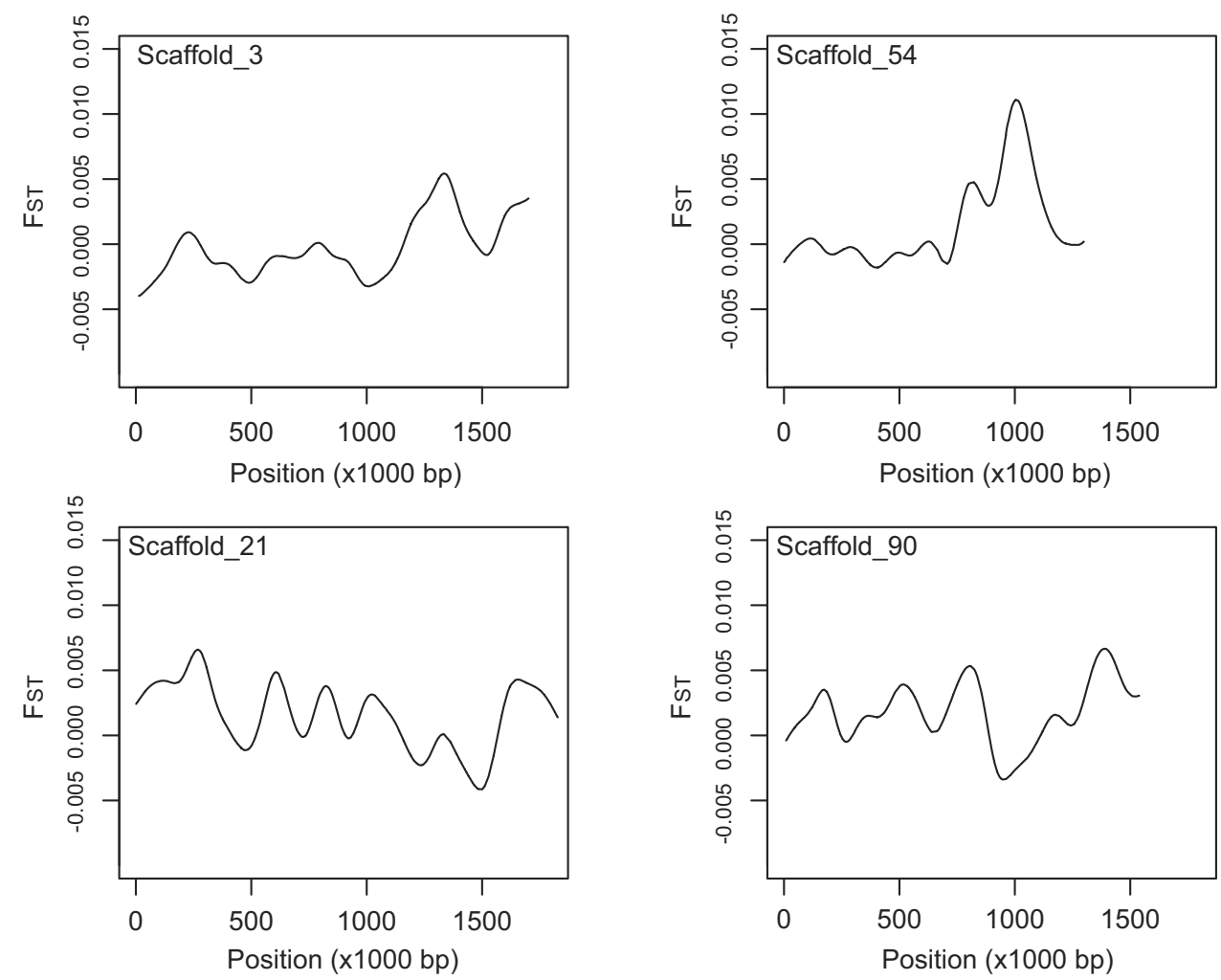

Figure 2. Sliding windows, with a window size of $50 \mathrm{~kb}$, of $F_{\mathrm{ST}}$ across four selected scaffolds in the European eel genome. Data from Pujolar et al. (2014a).

is likely that genome-wide coverage on population scales will provide important new insights on the number and size of genomic regions involved in population divergence and reproductive isolation in these and other marine fishes.

\section{Comparative population genomics}

Attaining genome-wide coverage in several species facilitates comparative approaches, for example, related to identifying genes, signaling pathways, or genomic regions involved in adaptive population divergence and speciation (Cutter and Payseur, 2013). Population genetic work applying smaller sets of genetic markers has shown the potential of these methods. For instance, parallel patterns of elevated population differentiation have been observed at heat-shock protein genes between the marine North Sea and the brackish Baltic Sea in European flounder (Hemmer-Hansen et al., 2007), Atlantic cod (Nielsen et al., 2009b), and Atlantic herring (Limborg et al., 2012; see also Fig. 3). Heat-shock proteins are important for buffering organisms and cells against external stress (Sørensen et al., 2003), and the finding of parallel patterns of variation in these genes across a shared environmental gradient is a strong indication of convergent adaptation to the different environmental conditions in the two areas.

In contrast, two recent studies did not find any overlap of loci under selection in different eel species. Gagnaire et al. (2012) scanned for signatures of single-generation selection in American eel (A. rostrata) using a panel of 100 SNPs. They found evidence for spatially varying selection at 13 loci showing correlations between allele frequencies and environmental variables across the entire species range. Using the same SNP panel, Ulrik et al. (2014) found significant genetic-by-environment associations at 10 of the loci in European eel, but none of these were the same loci that showed significant associations in American eel. The contrasting pattern of spatially varying selection in the two species suggests there are no apparent parallel patterns of selection in North Atlantic eels, at least at the level of the individual genes assessed in these studies. As an alternative to targeted candidate gene approaches, Pujolar et al. (2014a) tested for footprints of selection using 50,354 RAD-generated SNPs. Several markers showed evidence of divergent selection, associated with the highly variable environmental conditions experienced by the European eel along its geographic range. It remains to be seen whether any of these genomic regions are also under selection in the American eel.

\section{Added insights on ecological time scales}

It is becoming increasingly clear that evolutionary change may occur on contemporary time scales (Allendorf and 
a)

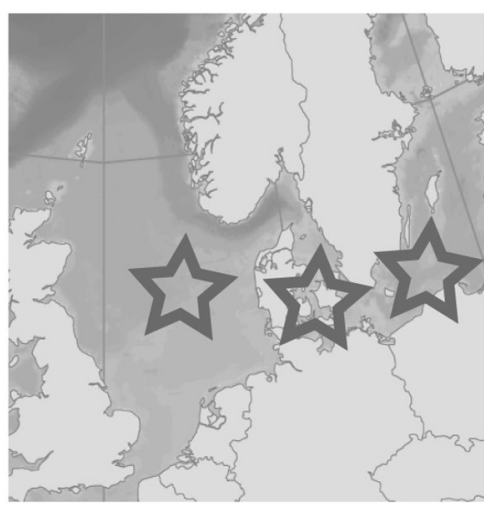

b)

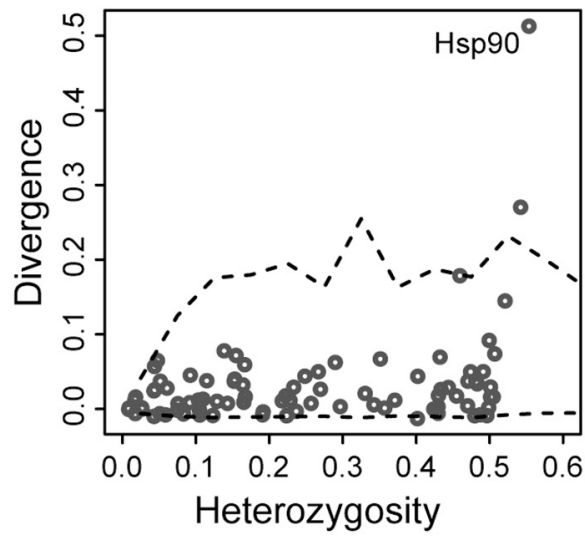

c)

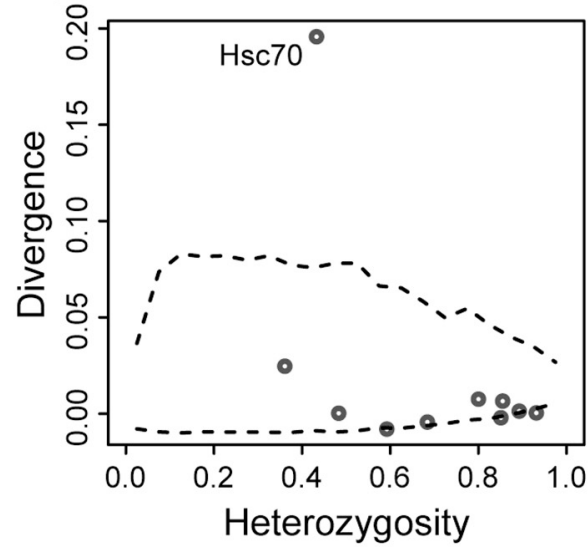

Figure 3. Population divergence between North Sea and Baltic Sea populations (sample sites shown in [a]) of Atlantic cod (b) and European flounder (c). Each circle represents one genetic marker. Confidence intervals (99.5\%), as estimated with the simulation-based $F_{\mathrm{ST}}$ outlier test FDIST (Beaumont and Nichols, 1996), for neutral divergence are indicated with broken lines. Markers located in or near the heat-shock protein genes Hsp90 and Hsc70 are labeled in (b) and (c), respectively. Data from Nielsen et al. (2009b) in (a) and Hemmer-Hansen et al. (2007) in (b). See Limborg et al. (2012) for similar results in Atlantic herring.

Hard, 2009; Schoener, 2011), and a major advantage of attaining more comprehensive coverage in genomic studies is the possibility of obtaining new insights that reflect shortterm eco-evolutionary dynamics. This information would also be relevant to fisheries conservation and management, which has traditionally focused on processes on ecological time scales but should ideally aim at conserving the longer term evolutionary potential of biological populations (see, e.g., Reiss et al., 2009; Schindler et al., 2010).

Several studies suggest that fishing pressure and climate change could act as drivers of evolutionary change on contemporary time scales in natural marine fish populations (Jørgensen et al., 2007; Baudron et al., 2014; Crozier and Hutchings, 2014). Consequently, evolutionary processes should ideally be incorporated into conservation and management practices to secure both the future evolutionary potential and sustainable exploitation of marine fishes (Hoffmann and Sgro, 2011; Heino et al., 2013). However, despite large quantities of phenotypic data, unequivocal evidence for recent genetic changes as a response to fishing pressure or temperature changes is still largely missing (Kuparinen and Merilä, 2007; Merilä and Hendry, 2014). Here, genomic data would greatly improve our ability to detect genetic change associated with specific environmental drivers and thereby to exclude alternative explanations, such as phenotypic plasticity and population replacement (Gienapp et al., 2008; Hansen et al., 2012; Therkildsen et al., 2013a; also see following section on spatio-temporal population genomics).

Reliable information about effective population sizes (Ne) and their changes are also important for assessing effects of fishing on genetic diversity and future evolutionary potential (Ovenden et al., 2013; Pinsky and Palumbi, 2014). However, short-term estimates of $\mathrm{Ne}$ in marine fishes are often associated with high uncertainty due to low signalto-noise ratios (see discussions in Poulsen et al., 2006, and Therkildsen et al., 2010). Genome-wide coverage may increase power and resolution for estimating these demographic parameters because it will reduce sampling error associated with examining only a small number of genomic locations (Allendorf et al., 2010; McCoy et al., 2014). In European eel, for example, SNP markers developed from sequenced RAD tags were recently used to estimate longterm effective population size to range between 132,000 and 1,320,000 individuals (depending on the mutation rate used; Pujolar et al., 2013a). These estimates are markedly higher than those obtained in previous studies that applied a limited number of microsatellite markers (Wirth and Bernatchez, 2003; Pujolar et al., 2011). Differences between studies are potentially attributable to microsatellite mutational properties and the lack of adequate mutation models to describe microsatellite evolution, which might have biased previous estimates (Pujolar et al., 2013a). Genome-wide SNP coverage would be expected to provide a more unbiased estimate of genomic variation in the species (Pujolar et al., 2013a), but it remains to be seen if these markers provide adequate power for accurately estimating short-term $\mathrm{Ne}$ - that is, the contemporary size relevant on ecological time scales.

Low levels of population differentiation, resulting from a lack of genome-wide migration-drift equilibrium due to recent divergence of large populations or high levels of gene flow (Nielsen et al., 2009a), have traditionally challenged 
the identification of biologically relevant population structuring in many marine fishes (Waples, 1998). With improved ability to detect shallow levels of population structuring and genomic regions under selection (Luikart et al., 2003; Allendorf et al., 2010), population genomic data should greatly enhance our ability to detect management units in marine fishes. Recent studies have illustrated the added resolution that can be attained with the use of markers that show elevated levels of population differentiation. Milano et al. (2014) investigated the population structure of European hake (Merluccius merluccius) using a panel of 381 SNPs. While neutral SNPs confirmed results from previous studies (Atlantic-Mediterranean genetic break), highly divergent outlier loci showed fine-scale structure and strong differentiation among the western, central, and eastern Mediterranean. In Atlantic cod, patterns of structuring were also found to be markedly different between putative neutral markers and highly differentiated markers located in candidate genes for growth and reproduction (HemmerHansen et al., 2014). Similar patterns have been found for other species, including Atlantic herring (Lamichhaney et al., 2012; Limborg et al., 2012). In such cases, inferred management units differ substantially depending on the markers employed, illustrating the power of combining markers that are sensitive to different evolutionary processes (Funk et al., 2012).

These examples illustrate that genetic markers in genomic regions under selection may serve as population tags in situations where much of the genome shows low levels of population differentiation (Hauser and Carvalho, 2008; Nielsen et al., 2012). These highly differentiated genetic markers provide unprecedented statistical power for individual assignment to population of origin (Nielsen et al., 2012). Consequently, genomic insights can also be exploited for inference on ecological time scales-for instance to estimate migration rates on contemporary time scales (Ovenden et al., 2013) or to develop practical tools for fisheries control and enforcement (Nielsen et al., 2012).

\section{Detecting and understanding hybridization}

Genome scan approaches can be very useful for studies of hybridization. Introgression is often difficult to detect genetically because introgressed individuals share most of their genome with one of the parental species or populations. Consequently, many genetic markers are necessary, especially when markers are highly polymorphic and not diagnostic, for example, microsatellites (Vähä and Primmer, 2006). Due to the low polymorphism and low homoplasy, SNPs are more likely to be diagnostic for hybridization studies, and initial screens of large parts of the genome can identify markers with the greatest diagnostic power. For example, diagnostic SNPs generated by RAD sequencing have been used to detect introgression between rainbow trout (Oncorhynchus mykiss) and westlope cutthroat trout (Oncorhynchus clarkii lewisi; Amish et al., 2012; Hohenlohe et al., 2013).

Marine fishes provide several valuable systems for studying hybridization between well-characterized species and populations within species. For instance, patterns of hybridization between the two North Atlantic eels, European ( $\mathrm{An}$ guilla anguilla) and American (A. rostrata) eel were recently investigated (Pujolar et al., 2014b). RAD sequences of both species were aligned and a total of 3348 diagnostic SNPs $\left(F_{\mathrm{ST}} 0.95\right)$ were identified. Genotyping of a subset of 96 diagnostic SNPs showed a $10.7 \%$ proportion of admixed individuals in Iceland, mostly including F1 hybrids, although second-generation backcrosses were also identified. By comparison, hybrids represented less than $0.5 \%$ in mainland Europe and were all late-generation backcrosses. These data suggest low but biologically significant gene flow (Pujolar et al., 2014b), which could explain the limited genetic differentiation between European and American eel $\left(F_{\mathrm{ST}}=0.09\right.$; Als et al., 2011). Other good examples of marine fish species in which genetic differentiation could be hampered by hybridization are plaice (Pleuronectes platesa) and flounder (Platichthys flesus) in Northern Europe (Kijewska et al., 2009), redfish species (Sebastes spp.) in the Northern Atlantic (Roques et al., 2001), and coral reef fishes in the Indo-Pacific (Hobbs et al., 2009). Moreover, several well-characterized intra-specific hybrid zones also provide valuable model systems for evolutionary studies in marine fishes (Nielsen et al., 2003, 2004; Durand et al., 2009). These could be used to identify genomic regions of reduced introgression that are potentially involved in maintaining reproductive isolation between parental populations (Gompert and Buerkle, 2011).

\section{Linking genotype and phenotype}

Identifying the genetic basis of specific traits is a major challenge, even in model species (Vasemägi and Primmer, 2005; Barrett and Hoekstra, 2011; Wray, 2013), and promising approaches to achieve this ambitious goal combine information from the fields of population genomics and quantitative genetics (Stinchcombe and Hoekstra, 2008). While several attributes of marine fishes render these species suitable for population genomic studies in natural populations (as reviewed in previous sections), the large effective population sizes indicate that family-based quantitative genetic approaches in natural populations (Slate, 2005; Schielzeth and Husby, 2014) may not be successful. Instead, culturing facilities available from extensive aquaculture programs in some marine fishes (e.g., Cerdà and Manchado, 2013) offer a resource that could be exploited to identify the genetic basis of phenotypes from controlled crosses (see Baird et al., 2008; Franchini et al., 2014). The large population sizes and associated high levels of recombination in 
natural populations also provide suitable settings for association mapping studies (Vasemägi and Primmer, 2005), provided that sufficiently dense genome coverage can be attained. Another particularly promising approach could be to use natural hybrid zones for admixture mapping (Buerkle and Lexer, 2008; Lindtke et al., 2013).

Under controlled environmental conditions, new and powerful methods for assessing phenotypic variation at the molecular level could also be exploited. The introduction of high-throughput next-generation sequencing technologies has revolutionized transcriptomics research by allowing RNA analysis through cDNA sequencing at massive scale (Wang et al., 2009). Therefore, it is not surprising that RNA-seq has become the technology of choice for quantifying differential gene expression (Deng et al., 2011; Smith et al., 2013). Gene expression analyses have allowed the identification of key molecular mechanisms underlying desired traits in farmed fish (Roberge et al., 2006; Ferraresso et al., 2008, 2013), but have also been successfully applied to natural populations of marine fishes (Whitehead and Crawford, 2006; Larsen et al., 2007, 2011; Bernatchez et al., 2011; Pujolar et al., 2012, 2013b; Côté et al., 2014). Finally, transcriptomic analyses can be complemented and integrated with protein expression analysis to investigate the responses at the proteomic level for a deeper understanding of functional implications (Nie et al., 2007; Dalziel and Schulte, 2012).

\section{Spatio-temporal population genomics}

Marine fishes provide exceptional opportunities for extending genomic analysis back in time because extensive collections of archived historical samples exist for several commercially and recreationally important species. These samples, typically in the form of scales or otoliths (earstones), were initially collected to study the age-distribution and growth patterns of fish stocks and therefore represent systematic and continuous time series dating back several decades, in some cases to the beginning of the 1900s. Few other taxa are represented by such comprehensive collections of historical material (Wandeler et al., 2007; Nielsen and Hansen, 2008), and this valuable resource makes it possible to directly track how allele frequencies have changed over time within populations - that is, to study microevolution directly in retrospective "real-time" (Hansen et al., 2012). Previous studies based on small marker sets have already taken advantage of this opportunity to shed light on demographic processes including estimates of effective population sizes, on the temporal stability of population structure and migration rates, on loss of diversity due to anthropogenic impacts, and even on effects of selection acting on specific candidate loci (reviewed in Wandeler et al., 2007; Nielsen and Hansen, 2008; Hansen et al., 2012).
Now with recent technological developments, it is becoming possible to achieve much denser genome coverage, even in studies involving historical samples. While the degraded nature of historical DNA poses a particular set of challenges and requires stringent data quality control and validation, a number of different methods can be used to obtain reliable high-throughput sequence or genotype data from ancient and historical samples (see Rizzi et al., 2012). We now have the technology to fully sequence the entire genome of samples that are thousands of years old (e.g., Rasmussen et al., 2010; Prüfer et al., 2014), and recent studies with archived fish samples or other museum specimens have generated high-quality data through minor methodological modifications using standard genotyping assays of 100s or 1000s of SNPs (e.g., Johnston et al., 2013; Therkildsen et al., 2013a, b), sequence capture methodology (Bi et al., 2012; Carpenter et al., 2013), or whole-genome sequencing (Rowe et al., 2011; Staats et al., 2013).

Obtaining denser genome coverage in studies of historical samples will make it possible to search for signs of selection over known time frames (i.e., between collected samples) with temporal genome scans (Hansen et al., 2012; Therkildsen et al., 2013a, b) and to identify genomic regions associated with very recent introgression between hybridizing species and populations (Bourret et al., 2011; Hufford et al., 2013). It will also provide unprecedented power to detect changes in the spatial distribution of different populations (Therkildsen et al., 2013a) and losses of unique population components (Nielsen and Bekkevold, 2012). The ability to extend genomic analysis back in time in many marine fish species therefore promises to provide important new insights about microevolutionary processes in natural populations over the years to come.

\section{Future Challenges and Opportunities}

\section{Fast linkage disequilibrium decay in marine fishes}

Due to the effects of effective population size on the level of linkage disequilibrium (Nordborg and Tavare, 2002; Slatkin, 2008), a fast decay of linkage disequilibrium should be generally expected in marine fishes. Since there is little published information available to assess whether this prediction holds true, we used data from two published studies to estimate levels of linkage disequilibrium in European eel (SNP data from a single geographical sample from Pujolar et al., 2014a) and Atlantic cod (SNP data from a single population sample from Hemmer-Hansen et al., 2013) as a function of distance between genetic markers. In European eel, we used the published genome sequence (Henkel et al., 2012a) to infer genomic location and found that linkage disequilibrium decayed to background levels, estimated as levels of linkage disequilibrium between non-syntenic markers, within a few kilobases (10-20 kb or less; Fig. 4a, b). This is in agreement with the high estimated effective 

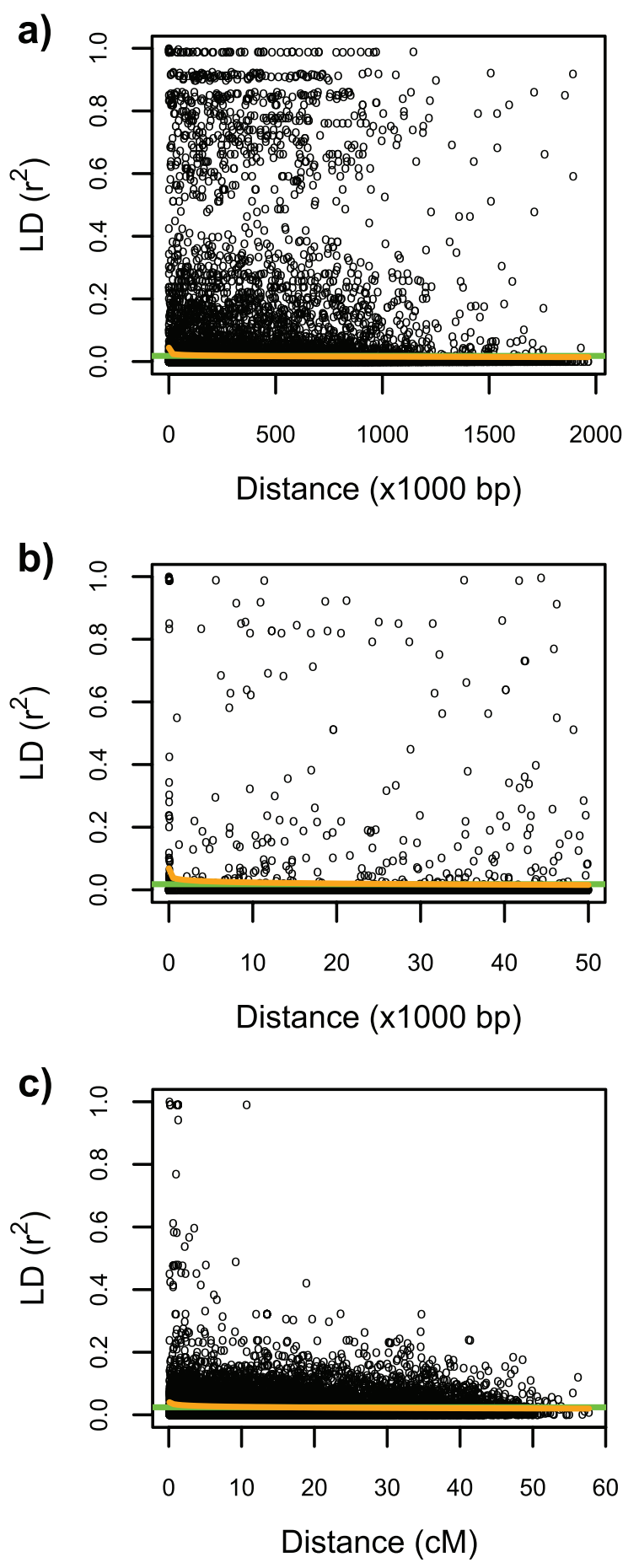

Figure 4. Linkage disequilibrium (LD) estimated as pairwise correlation coefficients $\left(r^{2}\right)$ between syntenic markers in European eel (a and b) and Atlantic cod (c) as a function of distance in base pairs (bp) in (a) and (b) or centimorgans (cM) in (c) between markers. In (a), a subset of 1500 single nucleotide polymorphisms in the 30 longest scaffolds was selected, while only marker pairs closer than $50 \mathrm{~kb}$ among the 1500 were used in (b). Green lines represent background levels of linkage disequilibrium, calculated as an average of estimates between non-syntenic markers. Orange lines are $\log$ trend lines fitted to the plotted syntenic marker estimates. Data from Pujolar et al. (2014a) in (a) and (b) and Hemmer-Hansen et al. (2013) in (c). population size in the species (Pujolar et al., 2013a). In Atlantic cod, we used the linkage map (Hubert et al., 2010) to examine the rate of linkage disequilibrium decay, since the combination of a relatively fragmented genome assembly (Star et al., 2011) and a modest number of assayed markers provided too few data points for robust inferences based on physical distance. Here, linkage disequilibrium decayed to background levels within a few centimorgans (cM), thus also suggesting a fast decay of linkage disequilibrium in this species. The lack of population genomic data of comparable quality in other species prevents any general conclusions about rates of linkage disequilibrium decay in marine fishes at present. However, assuming that most marine fish genomes are between $500 \mathrm{Mb}$ and $1 \mathrm{~Gb}$ (see Table 2) and that linkage disequilibrium decays to background levels within $1-20 \mathrm{~kb}$, the available data suggest that tens or more likely hundreds of thousands of markers will be needed to cover the genome comprehensively in these species. While the rapid linkage disequilibrium decay therefore increases the demand for high throughput in genomic studies of these species, it also implies that the effects of selection may be highly localized in their genomes because the extent of hitchhiking will be limited. Although selection does appear to sometimes affect large genomic blocks in marine fishes (see previous section), the general pattern of low linkage disequilibrium therefore offers promising prospects for identifying true targets of selection in these systems.

One advantage of new restriction-site-based genotyping approaches is that they can be tuned to target a specific number of sites in the genome, depending on the length of the enzyme recognition site (Hohenlohe et al., 2010). Thus, more markers can be assayed if an enzyme that makes frequent cuts is used in combination with larger volumes of sequencing, and a reference genome sequence can be used to estimate the number of markers generated with the use of specific enzymes (Lepais and Weir, 2014).

\section{Complex architecture and mechanism of adaptation}

Genome-wide data have changed our understanding of the genomic impacts of selection. It is becoming increasingly clear that classic hard selective sweeps (where a new advantageous mutation arises and spreads quickly to fixation, causing large reductions in genetic diversity in its vicinity due to hitchhiking effects) are relatively rare in natural populations of species surveyed so far (Pritchard $e t$ al., 2010; Messer and Petrov, 2013). Instead, adaptation often happens through minor shifts in allele frequency at many loci (polygenic selection) or through soft selective sweeps in which multiple adaptive haplotypes sweep through the population simultaneously and the effects on linked genetic variation are less pronounced than under hard sweeps (Hermisson and Pennings, 2005; Hancock et al., 2010; Pritchard et al., 2010). Furthermore, the evolutionary 
response of individual genes may depend on complex interactions with other genes within metabolic or signaling pathways as well as on genomic background within a population (Blount et al., 2012; Barrick and Lenski, 2013).

Selective sweeps tend to be soft when the targeted variants were already present in a population as standing genetic variation (and therefore have been recombined into several genetic backgrounds [haplotypes]) or had arisen independently on separate haplotypes by recurrent de novo mutations (Hermisson and Pennings, 2005). Since both the amount of standing genetic variation and the absolute number of mutations scale with population size, soft sweeps should be more likely in larger populations (Messer and Petrov, 2013), so we may expect this to be a common mode of adaptation in marine fish. Moreover, as polygenic selection often involves standing variation (Pritchard et al., 2010), this mechanism may also be important for adaptive response in highly variable marine fish populations.

Most tools for detecting selection in population genomic data have been developed to detect typical signatures of hard sweeps, and they may therefore miss much of the evidence for these other types of selection (Hancock et al., 2010; Messer and Petrov, 2013). Thus, new methods developed specifically for detecting polygenic adaptation (e.g., Coop et al., 2010; Bourret et al., 2014) and soft sweeps (e.g., Messer and Petrov, 2013; Ferrer-Admetlla et al., 2014) should complement more traditional approaches for further insights about how selection has shaped patterns of genomic variation.

In marine fishes, population genomic studies have often uncovered a large number of highly differentiated loci. However, few of these reflect fixed differences between populations (Nielsen et al., 2009b; Lamichhaney et al., 2012; Limborg et al., 2012; Hemmer-Hansen et al., 2013; Therkildsen et al., 2013a; Milano et al., 2014). This could suggest that classical hard complete sweeps are also not the most common mechanism underlying adaptive evolution in these species, although post-selection gene flow or ongoing selection-migration balance are also plausible explanations for these patterns.

Overall, we still know very little about the evolutionary forces and genomic mechanisms responsible for population divergence in these species as most high-throughput scans for selection have been based on markers with unknown genomic location or have used only unphased data that limit inference on haplotype patterns. The few available genomewide scans for selection in marine fishes have not provided conclusive evidence of a major mechanism underlying adaptation in these species, as both signals of highly localized differentiation and those of differentiation extending over larger genomic blocks have been reported (Jones et al., 2012; Lamichhaney et al., 2012; Hemmer-Hansen et al., 2013; Karlsen et al., 2013; Pujolar et al., 2014a). Only a few studies have applied a true genome resequencing approach
(Jones et al., 2012; Karlsen et al., 2013). In Atlantic cod, the study had the specific aim of assessing divergence between two well-known ecotypes (Karlsen et al., 2013), which may have diverged before the last glacial maximum (HemmerHansen et al., 2013). Thus, disclosing the mechanisms behind more recent divergent selection in this and other species is likely to require much higher densities of markers and combinations of more analysis methods than have so far been applied in comparisons of multiple populations.

\section{Lack of genomic reference}

Currently, most genomic studies in marine fishes do not have access to information about the genomic location of assayed markers. Thus, even though the generation of thousands of markers is technically feasible in most species, making true inferences about the genomic architecture underlying observed patterns of variation is often difficult.

Although technological developments, such as third-generation sequencing and specialized sequencing strategies, are facilitating genome sequencing and assembly in marine species that typically harbor very high levels of genetic variability (e.g., Zhang et al., 2012; Voskoboynik et al., 2013), de novo assembling a high-quality draft genome remains a nontrivial task that will likely be out of reach for most individual research projects in the nearest future. However, the rapidly emerging genomic resources in many marine fishes (Bernardi et al., 2012) should facilitate genomic studies in a broader set of related species. One good example of using the genome sequence from a closely related species as a reference is the case of the two North Atlantic eel species, the European eel (Anguilla anguilla) and the American eel (A. rostrata), sister species that diverged about 3 MYA (Jacobsen et al., 2014). Using RAD sequencing, a large proportion of sequence reads could be aligned to the European eel draft genome for both species, with only a slightly higher alignment success for European (67.16\%) than for American (61.33\%) eel (Pujolar et al., 2013a). Re-examination of the data by aligning the same RAD sequences to the Japanese eel (A. japonica) genome produced much lower alignment success, $48.96 \%$ for European and $46.68 \%$ for American eel. Nevertheless, alignment success was still reasonably high considering the basal position of Japanese eel within the phylogeny of the genus (Mineguishi et al., 2005). In another study, the distantly related three-spined stickleback genome was used to infer genomic location of exome regions in Atlantic herring (Lamichhaney et al., 2012). This study took advantage of the high degree of synteny of genomic organization that has been observed among fish species (Sarrapoulou and Fernandez, 2011). Thus, even though high-quality reference genomes may not be available to new species, it could still be possible to extract useful information from other available genomic resources. 
Information about the genomic location of individual markers could also be extracted from linkage maps, which are available for a number of marine fish species (see, e.g., Nielsen et al., 2009a; Cerdà and Manchado, 2013). These resources are often logistically challenging to produce because they require the generation of very high numbers of offspring from controlled laboratory crosses. However, because many marine organisms produce large numbers of offspring, the power of next-generation sequencing can also be exploited to generate linkage maps from single-generation crosses of wild-caught parents (Amores et al., 2011), thus avoiding the need to keep several families in culture for many generations.

\section{Conclusions}

Since individual research projects face trade-offs between quantities of data per individual and number of individuals assessed, each study involves important decisions regarding the approach used in relation to the specific questions asked. Clearly, the highest genomic resolution will be obtained by population-scale genome resequencing (Ellegren, 2014). It is likely that this level of resolution will be needed to obtain a detailed understanding of patterns of genomic variationfor instance to understand the importance of structural variation for local adaptation (Lawniczak et al., 2010; Jones et al., 2012). Less resolution obtained through sequencing restriction-enzyme-digested genomes (Davey et al., 2011) or transcriptomes (De Wit et al., 2012) will be highly informative for more general assessments of genomic architectures and patterns of variation. These data could provide important information about the number and size of genomic regions showing signatures of adaptive population divergence. Knowledge about the genomic location of assayed markers is imperative for tapping the full potential of these approaches, and could be achieved through access to full-genome reference sequences in target or closely related species. This development will be one of the most significant in the near future, truly allowing a transition from population genetics to population genomics in marine fishes (Luikart et al., 2003). However, even without full-genome sequences, the ability to assess variation in much higher numbers of markers will increase the precision of estimates of demographic parameters and the likelihood of identifying specific genes under selection (Funk et al., 2012).

As evidenced by the applications highlighted in this review, next-generation sequencing and genotyping technologies promise to advance population genomic research in marine fishes significantly. Importantly, the insights generated from this technological revolution will have general implications for our understanding of evolutionary processes on contemporary and historical time scales as well as for conservation and management of valuable marine resources.

\section{Acknowledgments}

The research leading to this publication has received funding from the European Community's Seventh Framework Programme (FP7/2007-2013) under grant agreement no. KBBE-212 399 (FishPopTrace) and from the Danish Ministry for Food, Agriculture and Fisheries and the European Union through the project "MSC certification of plaice fisheries in area IIIa-basic investigations and development of a management plan" (European Fisheries Fund: contract no. 33010-12-a-0253).

\section{Literature Cited}

Allendorf, F. W., and J. J. Hard. 2009. Human-induced evolution caused by unnatural selection through harvest of wild animals. Proc. Natl. Acad. Sci. USA 106 (Suppl 1): 9987-9994.

Allendorf, F. W., P. A. Hohenlohe, and G. Luikart. 2010. Genomics and the future of conservation genetics. Nat. Rev. Genet. 11: 697-709.

Als, T. D., M. M. Hansen, G. E. Maes, M. Castonguay, L. Riemann, K. Aarestrup, P. Munk, H. Sparholt, R. Hanel, and L. Bernatchez. 2011. All roads lead to home: panmixia of European eel in the Sargasso Sea. Mol. Ecol. 20: 1333-1346.

Amemiya, C. T., J. Alföldl, A. P. Lee, S. Fan, H. Philippe, I. MacCallum, I. Braasch, T. Manousaki, I. Schneider, N. Rohner et al. 2013. The African coelacanth genome provides insights into tetrapod evolution. Nature 496: 311-316.

Amish, S. J., P. A. Hohenlohe, S. Painter, R. F. Leary, C. Muhlfeld, F. W. Allendorf, and G. Luikart. 2012. RAD sequencing yields a high success rate for westslope cutthroat and rainbow trout speciesdiagnostic SNP assays. Mol. Ecol. Res. 12: 653-660.

Amores, A., J. Catchen, A. Ferrara, Q. Fontenot, and J. H. Postlethwait. 2011. Genome evolution and meiotic maps by massively parallel DNA sequencing: spotted gar, an outgroup for the teleost genome duplication. Genetics 188: 799-808.

Aparicio, S., J. Chapman, E. Stupka, N. Putman, J. M. Chia, P. Dehal, A. Christoffels, S. Rash, S. Hoon, A. Smit et al. 2002. Wholegenome shotgun assembly and analysis of the genome of Fugu rubripes. Science 297: 1301-1310.

Baird, N. A., P. D. Etter, T. S. Atwood, M. C. Currey, Z. A. Lewis, E. Y. Selker, W. A. Cresko, and E. A. Johnson. 2008. Rapid SNP discovery and genetic mapping using sequenced RAD markers. PLoS One 3: e3376.

Barrett, R. D., and H. E. Hoekstra. 2011. Molecular spandrels: tests of adaptation at the genetic level. Nat. Rev. Genet. 12: 767-780.

Barrick, J. E., and R. E. Lenski. 2013. Genome dynamics during experimental evolution. Nat. Rev. Genet. 14: 827-839.

Baudron, A. R., C. L. Needle, A. D. Rijnsdorp, and C. T. Marshall. 2014. Warming temperatures and smaller body sizes: synchronous changes in growth of North Sea fishes. Glob. Change Biol. 20: 1023 1031.

Beaumont M., and R. Nichols. 1996. Evaluating loci for use in the genetic analysis of population structure. Proc. R. Soc. B Biol. Sci. 263: 1619-1626.

Bernardi, G. 2013. Speciation in fishes. Mol. Ecol. 22: 5487-5502.

Bernardi, G., E. O. Wileu, H. Mansour, M. R. Miller, G. Orti, D. Haussler, S. J. O'Brien, O. A. Ryder, and B. Venkatesh. 2012. The fishes of genome 10K. Mar. Genomics 7: 3-6.

Bernatchez, L., J. St-Cyr, E. Normandeau, G. E. Maes, T. D. Als, S. Kalujnaia, G. Cramb, M. Castonguay, and M. M. Hansen. 2011. Differential timing of gene expression regulation between leptocephali of the two Anguilla eel species in the Sargasso Sea. Ecol. Evol. 1: $459-468$. 
Bi, K., D. Vanderpool, S. Singhal, T. Linderoth, C. Moritz, and J. M. Good. 2012. Transcriptome-based exon capture enables highly costeffective comparative genomic data collection at moderate evolutionary scales. BMC Genomics 13: 403.

Blount, Z. D., J. E. Barrick, C. J. Davidson, and R. E. Lenski. 2012. Genomic analysis of a key innovation in an experimental Escheria coli population. Nature 489: 513-518.

Borza, T., B. Higgins, G. Simpson, and S. Bowman. 2010. Integrating markers Pan I and haemoglobin with the genetic linkage map of Atlantic cod (Gadus morhua). BMC Res. Notes 3: 261.

Bourret, V., P. T. O'Reilly, J. W. Carr, P. R. Berg, and L. Bernatchez. 2011. Temporal change in genetic integrity suggests loss of local adaptation in a wild Atlantic salmon (Salmo salar) population following introgression by farmed escapees. Heredity 106: 500-510.

Bourret, V., M. Dionne, M. P. Kent, S. Lien, and L. Bernatchez. 2013. Landscape genomics in Atlantic salmon (Salmo salar): searching for gene-environment interactions driving local adaptation. Evolution 67: 3469-3487.

Bourret, V., M. Dionne, and L. Bernatchez. 2014. Detecting genotypic changes associated with selective mortality at sea in Atlantic salmon: polygenic multilocus analysis surpasses genome scan. Mol. Ecol. 23: 4444-4457. doi:10.1111/mec. 12798

Bradbury, I. R., S. Hubert, B. Higgins, S. Bowman, T. Borza, I. G. Paterson, P. V. Snelgrove, C. J. Morris, R. S. Gregory, D. Hardle et al. 2013. Genomic islands of divergence and their consequences for the resolution of spatial structure in an exploited marine fish. Evol. Appl. 6: $450-461$.

Buerkle, C. A., and C. Lexer. 2008. Admixture as the basis for genetic mapping. Trends Ecol. Evol. 23: 686-694.

Carlsson, J., D. T. Gauthier, J. E. Carlsson, J. P. Coughlan, F. Dillane, R. D. Fitzgerald, U. Keating, P. McGinnity, L. Mirimin, and T. F. Cross. 2013. Rapid, economical single-nucleotide polymorphism and microsatellite discovery based on de novo assembly of a reduced representation genome in a non-model organism: a case study of Atlantic cod Gadus morhua. J. Fish Biol. 82: 944-958.

Carpenter, M. L., J. D. Buenrostro, C. Valdiosera, H. Schroeder, M. E. Allentoft, M. Sikora, M. Rasmussen, S. Gravel, S. Guillén, G. Nekhrizov et al. 2013. Pulling out the 1\%: whole-genome capture for the targeted enrichment of ancient DNA sequencing libraries. Am. J. Hum. Genet. 93: 852-864.

Cerdà, J., and M. Machado. 2013. Advances in genomics for flatfish aquaculture. Genes Nutr. 8: 5-17.

Charlesworth, B., M. Nordberg, and D. Charlesworth. 1997. The effects of local selection, balanced polymorphism and background selection on equilibrium patterns of genetic diversity in subdivided populations. Genet. Res. 70: 155-174.

Chen, S., G. Zhang, C. Shao, Q. Huang, G. Liu, P. Zhang, W. Song, N. An, D. Chalopin, J. N. Volff et al. 2014. Whole-genome sequence of a flatfish provides insights into $\mathrm{ZW}$ sex chromosome evolution and adaptation to benthic lifestyle. Nat. Genet. 46: 253-260.

Colosimo, P. F., K. E. Hosemann, W. Balabhadra, G. Villarreal, M. Dickson, J. Grimwood, J. Schmutz, R. M. Myers, D. Schluter, and D. M. Kingsley. 2005. Widespread parallel evolution in sticklebacks by repeated fixation of Ectodysplasin alleles. Science 307: 1928-1933.

Coop, G., D. Witonsky, A. Di Rienzo, and J. K. Pritchard. 2010. Using environmental correlations to identify loci underlying local adaptation. Genetics 185: 411-1423.

Corander, J., K. K. Majander, L. Cheng, and J. Merilä. 2013. High degree of cryptic population differentiation in the Baltic Sea herring Clupea harengus. Mol. Ecol. 22: 2931-2940.

Côté, C. L., M. Castonguay, S. Kalujnaia, G. Cramb, and L. Bernatchez. 2014. In absence of local adaptation, plasticity and spatially varying selection rule: a view from genomic reaction norms in a panmictic species (Anguilla rostrata). BMC Genomics 15: 403.
Crozier L. G., and J. A. Hutchings. 2014. Plastic and evolutionary responses to climate change in fish. Evol. Appl. 7: 68-87.

Cruickshank, T. E., and M. W. Hahn. 2014. Reanalysis suggests that genomic islands of speciation are due to reduced diversity, not reduced gene flow. Mol. Ecol. 23: 3133-3157.

Cutter, A. D., and B. A. Payseur. 2013. Genomic signatures of selection at linked sites: unifying disparity among species. Nat. Rev. Genet 14: $262-274$

Dalziel, A. C., and P. M. Schulte. 2012. Ecological proteomics: finding molecular markers that matter. Mol. Ecol. 21: 3382-3384.

Davey, J. W., P. A. Hohenlohe, P. D. Etter, J. Q. Boone, J. M. Catchen, and M. L. Blaxter. 2011. Genome-wide genetic marker discovery and genotyping using next-generation sequencing. Nat. Rev. Genet. 12: 499-510.

Deagle, B. E., F. C. Jones, D. M. Absher, D. M. Kingsley, and T. E. Reimchen. 2013. Phylogeography and adaptation genetics of stickleback from the Haida Gwaii archipelago revealed using genome-wide single nucleotide polymorphism genotyping. Mol. Ecol. 22: 19171932

Deng, X., J. B. Hiatt, D. K. Nguyen, S. Ercan, D. Sturgill, L. W. Hillier, F. Schlesinger, C. A. Davis, V. J. Reinke, T. R. Gingeras et al. 2011. Evidence for compensatory upregulation of expressed X-linked genes in mammals, Caenorhabditis elegans and Drosophila melanogaster. Nat. Genet. 43: 1179-1185.

De Wit, P., M. H. Pespeni, J. T. Ladner, D. J. Barshis, F. Seneca, H. Jaris, N. O. Therkildsen, M. Morikawa, and S. Palumbi. 2012. The simple fool's guide to population genomics via RNA-Seq: an introduction to high-throughput sequencing data analysis. Mol. Ecol. Res. 12: 1058-1067.

De Woody, J. A., and J. C. Avise. 2000. Microsatellite variation in marine, freshwater and anadromous fishes compared with other animals. J. Fish Biol. 56: 461-473.

Durand, E., F. Jay, O. E. Gaggiotti, and O. Francois. 2009. Spatial inference of admixture proportions and secondary contact zones. Mol. Biol. Evol. 26: 1963-1973.

Ellegren, H. 2014. Genome sequencing and population genomics in non-model organisms. Trends Ecol. Evol. 29: 51-63.

Feder, J. L., and P. Nosil. 2010. The efficacy of divergence hitchhiking in generating genomic islands during ecological speciation. Evolution 64: 1729-1747.

Feder, J. L., S. P. Egan, and P. Nosil. 2012. The genomics of speciation-with-gene-flow. Trends Genet. 28: 342-350.

Ferraresso, S., N. Vitulo, A. N. Mininni, C. Romualdi, B. Cardazzo, E. Negrisolo, R. Reinhardt, A. V. Canario, T. Patarnello, and L. Bargelloni. 2008. Development and validation of a gene expression oligo microarray for the gilthead sea bream (Sparus aurata). BMC Genomics 9: 580.

Ferraresso, S., A. Bonaldo, L. Parma, S. Cinotti, P. Massi, L. Bargelloni, nd P. P. Gatta. 2013. Exploring the larval transcriptome of the common sole (Solea solea). BMC Genomics 14: 315.

Ferrer-Admetlla, A., M. Liang, T. Korneliussen, and R. Nielsen. 2014. On detecting incomplete soft or hard selective sweeps using haplotype structure. Mol. Biol. Evol. 31: 1275-1291.

Flaxman, S. M., J. L. Feder, and P. Nosil. 2013. Genetic hitchhiking and the dynamic buildup of genomic divergence during speciation with gene flow. Evolution 67: 2577-2591.

Franchini P., C. Fruciano, M. L. Spreitzer, J. C. Jones, K. R. Elmer, F. Henning, and A. Meyer. 2014. Genomic architecture of ecologically divergent body shape in a pair of sympatric crater lake cichlid fishes. Mol. Ecol. 23: 1828-1845.

Funk, C. W., J. K. McKay, P. A. Hohenlohe, and F. W. Allendorf. 2012. Harnessing genomics for delineating conervation units. Trends Ecol. Evol. 27: 489-496. 
Gagnaire, P. A., E. Normandeau, C. Côté, M. M. Hansen, and L. Bernatchez. 2012. The genetic consequences of spatially varying selection in the panmictic American eel (Anguilla rostrata). Genetics 190: $725-736$

Gienapp, P., C. Teplitsky, J. S. Alho, J. A. Mills, and J. Merilä. 2008. Climate change and evolution: disentangling environmental and genetic responses. Mol. Ecol. 17: 167-178.

Gompert, Z., and C. A. Buerkle. 2011. Bayesian estimation of genomic clines. Mol. Ecol. 20: 2111-2127.

Good, J. M. 2011. Reduced representation methods for subgenomic enrichment and next-generation sequencing. Methods Mol. Biol. 772: 85-103.

Grover, C. E., A. Salmon, and J. F. Wendel. 2012. Targeted sequence capture as a powerful tool for evolutionary analysis. Am. J. Bot. 99: 312-319.

Hancock, A. M., G. Alkorta-Aranburu, D. B. Witonsky, and A. Di Rienzo. 2010. Adaptations to new environments in humans: the role of subtle allele frequency shifts. Philos. Trans. R. Soc. B 365: 24592468.

Hancock, A. M., D. B. Witonsky, G. Alkorta-Aranburu, C. M. Beall, A. Gebremedhin, R. Sukernik, G. Utermann, J. K. Pritchard, G. Coop, and A. Di Rienzo. 2011. Adaptations to climate-mediated selective pressures in humans. PLoS Genet. 7: e1001375.

Hansen, M. M., I. Olivieri, D. M. Waller, E. E. Nielsen, GeM Working Group. 2012. Monitoring adaptive genetic responses to environmental change. Mol. Ecol. 21: 1311-1329.

Hauser, L., and G. R. Carvalho. 2008. Paradigm shifts in marine fisheries genetics: ugly hypotheses slain by beautiful facts. Fish Fish. 9: $333-362$.

Heino, M., L. Baulier, D. S. Boukal, B. Ernande, F. D. Johnston, F. M. Mollet, H. Pardoe, N. O. Therkildsen, S. Uusi-Heikkilä, and A. Vainikka et al. 2013. Can fisheries-induced evolution shift reference points for fisheries? ICES J. Mar. Sci. 70: 707-721.

Helyar, S. J., M. T. Limborg, D. Bekkevold, M. Babbucci, J. van Houdt, G. E. Maes, L. Bargelloni, R. O. Nilesen, M. I. Taylor, R. Ogden et al. 2012. SNP discovery using next generation transcriptomic sequencing in Atlantic herring (Clupea harengus). PLoS One 7: e42089.

Hemmer-Hansen, J., E. E. Nielsen, J. Frydenberg, and V. Loeschcke. 2007. Adaptive divergence in a high gene flow environment: Hsc70 variation in the European flounder (Platichthys flesus). Heredity 99: 592-600.

Hemmer-Hansen, J., E. E. Nielsen, N. O. Therkildsen, M. I. Taylor, R. Ogden, A. J. Geffen, D. Bekkevold, S. Helyar, C. Pampoulie, T. Johansen et al. 2013. A genomic island linked to ecotype divergence in Atlantic cod. Mol. Ecol. 22: 2653-2667.

Hemmer-Hansen, J., N. O. Therkildsen, D. Meldrup, and E. E. Nielsen. 2014. Conservation marine biodiversity: insights from life-history trait candidate genes in Atlantic cod (Gadus morhua). Conserv. Genet. 15: 213-228.

Henkel, C. V., E. Burgerhout, D. L. de Wijze, R. P. Dirks, Y. Minegishi, H. J. Jansen, H. P. Spaink, S. Dufour, F. A. Weltzien, K. Tsukamoto et al. 2012a. Primitive duplicate hox clusters in the European eel's genome. PLoS One 7: e32231.

Henkel, C. V., R. P. Dirks, D. L. de Wijze, Y. Minegishi, J. Aoyama, H. J. Jansen, B. Turner, B. Knudsen, M. Bundgaard, K. L. Hvam et al. 2012b. First draft genome sequence of the Japanese eel, Anguilla japonica. Gene 511: 195-201.

Hermisson, J., and P. S. Pennings. 2005. Soft sweeps: molecular population genetics of adaptation from standing genetic variation. Genetics 169: 2335-2352.

Hobbs, J. P. A., A. J. Frisch, G. R. Allen, and L. Van Herwerden. 2009. Marine hybrid hotspot at Indo-Pacific biogeographic border. Biol. Lett. 5: $258-261$
Hoffmann, A. A., and C. M. Sgrò. 2011. Climate change and evolutionary adaptation. Nature 470: 479-485.

Hohenlohe, P. A., S. Basshan, P. D. Etter, N. Stiffler, E. A. Johnson, and W. A. Cresko. 2010. Population genomics of parallel adaptation in threespine stickleback using sequenced RAD tags. PLoS Genet. 6: e1000862.

Hohenlohe, P. A., M. D. Day, S. J. Amish, M. R. Miller, N. KampsHugues, M. C. Boyer, C. C. Muhlfeld, F. W. Allendorf, E. A. Johnson, and G. Luikart. 2013. Genomics patterns of introgression in rainbow and westlope cutthroat trout illuminated by overlapping paired-end RAD sequencing. Mol. Ecol. 22: 3002-3013.

Hubert, S., B. Higgins, T. Borza, and S. Bowman. 2010. Development of a SNP resource and a genetic linkage map for Atlantic cod (Gadus mоrhиа). BMC Genomics 11: 191.

Hufford, M. B., P. Lubinksy, T. Pyhärvi, M. T. Devengenzo, N. C. Ellstrand, and J. Ross-Ibarra. 2013. The genomic signature of crop-wild introgression in maize. PLoS Genet. 9: e1003477.

Jackson, A. M., B. X. Semmens, Y. Sadovy de Mitcheson, R. S. Nemeth, S. A. Heppell, P. G. Bush, A. Aguilar-Perera, J. A. Claydon, M. C. Calosso, K. S. Sealey et al. 2014. Population structure and phylogeography in Nassau grouper (Epinephelus striatus), a massaggregating marine fish. PLoS One 9: e97508.

Jacobsen, M. W., J. M. Pujolar, T. P. Gilbert, J. V. M. Mayar, L. Bernatchez, T. D. Als, and M. M. Hansen. 2014. Speciation and demographic history of Atlantic eels (Anguilla anguilla and A. rostrata) revealed by mitogenome sequencing. Heredity doi: 10.1038/ hdy.2014.44.

Johnston, S. E., M. Lindqvist, E. Niemelä, P. Orell, J. Erkinaro, M. P. Kent, S. Lien, J.-P. Vähä, A. Vasemagi, and C. R. Primmer. 2013. Fish scales and SNP chips: SNP genotyping and allele frequency estimation in individual and pooled DNA from historical samples of Atlantic salmon (Salmo salar). BMC Genomics $14: 439$.

Jones, F. C., M. G. Grabherr, Y. F. Chan, P. Russell, E. Maucelli, J. Johnson, R. Swofford, M. Pirun, M. C. Zody, S. White et al. 2012. The genomic basis of adaptive evolution in threespine sticklebacks. Nature 484: 55-61.

Jørgensen, C., K. Enberg, E. S. Dunlop, R. Arlinghaus, D. S. Boukal, K. Brander, B. Ernande, A. Grodmark, F. Johnston, S. Matsumura et al. 2007. Managing evolving fish stocks. Science 318: 1247-1248.

Karlsen, B. O., K. Klingan, Å. Emblem, T. E. Jørgensen, A. Jueterbock, T. Furmanek, G. Hoarau, S. D. Johansen, J. T. Nordeide, and T. Moum. 2013. Genomic divergence between the migratory and stationary ecotypes of Atlantic cod. Mol. Ecol. 22: 5098-5111.

Kasahara, M., K. Naruse, S. Sasaki, Y. Nakatani, W. Qu, B. Ahsan, T. Yamada, Y. Nagayasu, K. Doi, Y. Kasai et al. 2007. The medaka draft genome and insights into vertebrate genome evolution. Nature 447: 714-719.

Kawecki, T. J., and D. Ebert. 2004. Conceptual issues in local adaptation. Ecol. Lett. 7: 1225-1241.

Kijewska, A., A. Burzynski, and R. Wenne. 2009. Molecular identification of European flounder (Platichthys flesus) and its hybrids with European plaice (Pleuronectes platessa). ICES J. Mar. Sci. 66: 902906.

Kondrashov, A. S., and F. A. Kondrashov. 1999. Interactions among quantitative traits in the course of sympatric speciation. Nature 400: 351-354.

Kuparinen, A., and J. Merila. 2007. Detecting and managing fisheries induced evolution. Trends Ecol. Evol. 22: 652-659.

Lamichhaney, S., A. Martinez Barrio, N. Rafati, G. Sundström, C. J. Rubin, E. R. Gilbert, J. Berglund, A, Wetterbom, L. Laikre, M. T. Webster et al. 2012. Population-scale sequencing reveals genetic differentiation due to local adaptation in Atlantic herring. Proc. Natl. Acad. Sci. USA 109: 1-6. 
Larsen, P. F., E. E. Nielsen, T. D. Williams, J. Hemmer-Hansen, J. K. Chipman, M. Kruhoffer, P. Gronkjaer, S. G. George, L. Dyrskjot, and V. Loeschcke. 2007. Adaptive differences in gene expression in European flounder (Platichthys flesus). Mol. Ecol. 16: 4674-4683.

Larsen, P. F., P. M. Schulte, and E. E. Nielsen. 2011. Gene expression analysis for the identification of selection and local adaptation in fishes. J. Fish Biol. 78: 1-22.

Lawniczak M. K. N., S. J. Emrich, A. K. Jholloway, A. P. Regier, M. Olson, B. White, S. Redmond, L. Fulton, E. Appelbaum, J. Godfrey et al. 2010. Widespread divergence between incipient Anopheles gambiae species revealed by whole genome sequences. Science 330: $512-514$.

Lepais, O., and J. T. Weir. 2014. SimRAD: an R package for simulation-based prediction of the number of loci expected in RADseq and similar genotyping by sequencing approaches. Mol. Ecol. Resour. doi: 10.1111/1755-0998.12273.

Limborg, M. T., S. J. Helyar, M. De Bruyn, M. I. Taylor, E. E. Nielsen, R. Ogden, G. R. Carvalho, FPT Consortium, and D. Bekkevold. 2012. Environmental selection on transcriptome-derived SNPs in a high gene flow marine fish, the Atlantic herring (Clupea harengus). Mol. Ecol. 21: 3686-3703.

Lindtke, D., S. C. Gonzalez-Martinez, D. Macaya-Saez, and C. Lexer. 2013. Admixture mapping of quantitative traits in Populus hybrid zones: power and limitations. Heredity 111: 474-485.

Luikart, G., P. R. England, D. Tallmon, S. Jordan, and P. Taberlet. 2003. The power and promise of population genomics: from genotyping to genome typing. Nat. Rev. Genet. 4: 981-994.

McCoy R. C., N. R. Garud, J. L. Kelley, C. L. Boggs, and D. A. Petrov. 2014. Genomic inference accurately predicts the timing and severity of a recent bottleneck in a nonmodel insect population. Mol. Ecol. 23: $136-150$.

Merilä, J., and A. P. Hendry. 2014. Climate change, adaptation, and phenotypic plasticity: the problem and the evidence. Evol. Appl. 7: $1-14$.

Messer, P. W., and D. A. Petrov. 2013. Population genomics of rapid adaptation by soft selective sweeps. Trends Ecol. Evol. 28: 659-669.

Milano, I., M. Babbucci, F. Panitz, R. Ogden, R. O. Nielsen, M. I. Taylor, S. J. Helyar, G. R. Carvalho, M. Espineira, M. Atanassova et al. 2011. Novel tools for conservation genomics: comparing two high-throughput approaches for SNP discovery in the transcriptome of the European hake. PloS One 6: e28008.

Milano, I., M. Babbucci, A. Cariani, M. Atanassova, D. Bekkevold, G. R. Carvalho, M. Espineira, F, Fiorentino, G. Garofalo, A. J. Geffen et al. 2014. Outlier SNP markers reveal fine-scale genetic structuring across European hake populations (Merluccius merluccius). Mol. Ecol. 23: 118-135.

Miller, M. R., J. P. Dunham, A. Amores, W. A. Cresko, and E. A. Johnson. 2007. Rapid and cost-effective polymorphism identification and genotyping using restriction sire associated DNA (RAD) markers. Genome Res. 17: 240-248.

Mineguishi, Y., J. Aoyama, J. G. Inoue, M. Miya, M. Nishida, and K. Tsukamoto. 2005. Molecular phylogeny and evolution of the freshwater eels genus Anguilla based on the whole mitochondrial genome sequences. Mol. Phylogenet. Evol. 34: 134-146.

Moen, T., M. Delghandi, M. S. Wesmajervi, J. I. Westgaard, and K. T. Fjalestad. 2009. A SNP/microsatellite genetic linkage map of the Atlantic cod (Gadus morhua). Anim. Genet. 40: 993-996.

Montes, I., D. Conklin, A. Albaina, S. Creer, G. R. Carvalho, M. Santos, and A. Estonba. 2013. SNP discovery in European anchovy (Engraulis encrasicolus) by high-throughput transcriptome and genome sequencing. PLoS One 8: e70051.

Nakamura, Y., K. Mori, K. Saitoh, K. Oshima, M. Mekuchi, T. Sugaya, Y. Shigenobu, N. Ojima, S. Muta, A. Fujiwara et al. 2013. Evolutionary changes of multiple visual pigment genes in the complete genome of Pacific bluefin tuna. Proc. Natl. Acad. Sci. USA 110: 11061-11066.

Narum, S. R., C. A. Buerkle, J. W. Davey, M. R. Miller, and P. A. Hohenlohe. 2013. Genotyping-by-sequencing in ecological and conservation genomics. Mol. Ecol. 22: 2841-2847.

Nie, L., G. Wu, D. E. Cudley, J. C. Scholten, and W. Zhang. 2007. Integrative analysis of transcriptomic and proteomic data: challenges, solutions and applications. Crit. Rev. Biotechnol. 27: 63-75.

Nielsen, E. E., and D. Bekkevold. 2012. The memory remains: application of historical DNA for scaling biodiversity loss. Mol. Ecol. 21: $1539-1541$.

Nielsen, E. E., and M. M. Hansen. 2008. Waking the dead: the value of population genetic analyses of historical samples. Fish Fish. 9: 450461.

Nielsen, E. E., M. M. Hansen, D. E. Ruzzante, D. Meldrup, and P. Grønkjœr. 2003. Evidence of a hybrid-zone in Atlantic cod (Gadus morhua) in the Baltic and the Danish Belt Sea revealed by individual admixture analysis. Mol. Ecol. 12: 1497- 1508.

Nielsen, E. E., P. H. Nielsen, D. Meldrup, and M. M. Hansen. 2004. Genetic population structure of turbot (Scophthalmus maximus) supports the presence of multiple hybrid zones for marine fishes in the transition zone between the Baltic Sea and the North Sea. Mol. Ecol. 13: $585-595$.

Nielsen, E. E., J. Hemmer-Hansen, P. F. Larsen, and D. Bekkevold. 2009a. Population genomics of marine fishes: identifying adaptive variation in space and time. Mol. Ecol. 18: 3128-3150.

Nielsen, E. E., J. Hemmer-Hansen, N. A. Poulsen, V. Loeschcke, T. Moen, T. Johansen, C. Mittelholzer, G. L. Taranger, R. Ogden, and G. R. Carvalho. 2009b. Genetic signatures of local directional selection in a high gene flow marine organism, the Atlantic cod (Gadus morhua). BMC Evol. Biol. 9: 276.

Nielsen, E. E., A. Cariani, E. Mac Aoidh, G. E. Maes, I. Milano, R. Ogden, M. Taylor, J. Hemmer-Hansen, M. Babbucci, L. Bargelloni et al. 2012. Gene-associated markers provide tools for tackling illegal fishing and false eco-certification. Nat. Coтmun. 3: 851.

Nielsen, R. 2005. Molecular signatures of natural selection. Annu. Rev. Genet. 39: 197-218.

Nordborg, M., and S. Tavaré. 2002. Linkage disequilibrium: what history has to tell us. Trends Genet. 18: 83-90.

Ovenden, J. R., O. Berry, D. J. Welch, R. C. Buckworth, and C. M. Dichmont. 2013. Ocean's eleven: a critical evaluation of the role of population, evolutionary and molecular genetics in the management of wild fisheries. Fish Fish. doi: 10.1111/faf.12052.

Palaiokostas, C., M. Bekaert, A. Davie, M. E. Cowan, M. Oral, J. B. Taggart, E. Gharbi, B. J. McAndrew, D. J. Penman, and H. Migaud. 2013. Mapping the sex determination locus in the Atlantic halibut (Hippoglossus hippoglossus) using RAD sequencing. BMC Genomics 14: 566

Peterson, B. K., J. N. Weber, E. H. Kay, H. S. Fisher, and H. E. Hoekstra. 2012. Double digest RADseq: an inexpensive method for de novo SNP discovery and for genotyping in model and non-model species. PloS One 7: e37135.

Pinsky, M. L., and S. R. Palumbi. 2014. Meta-analysis reveals lower genetic diversity in overfished populations. Mol. Ecol. 23: 29-39.

Poulsen, N. A., E. E. Nielsen, M. H. Schieruo, V. Loeschcke, and P. Grønkjœr. 2006. Long-term stability and effective population size in North Sea and Baltic Sea cod (Gadus morhua). Mol. Ecol. 15: 321331.

Prado-Martinez, J., I. Hernando-Herraez, B. Lorente-Galdos, M. Dabad, O. Ramirez, C. Baeza-Delgado, C. Morcillo-Suarez, C. Alkan, F. Hormozdiari, E. Raineri et al. 2013. The genome sequencing of an albino Western lowland gorilla reveals inbreeding in the wild. BMC Genomics 14: 363. 
Pritchard, J. K., J. K. Pickrell, and G. Coop. 2010. The genetics of human adaptation: hard sweeps, soft sweeps, and polygenic adaptation. Curr. Biol. 20: R208-R215.

Prüfer, K., F. Racimo, N. Patterson, F. Jay, S. Sankararaman, S. Sawyer, A. Heinze, G. Renaud, P. H. Sudmant, C. de Filippo et al. 2014. The complete genome sequence of a Neanderthal from the Altai Mountains. Nature 505: 43-49.

Pujolar, J. M., D. Bevacqua, F. Cappocioni, E. Ciccotti, G. A. De Leo, and L. Zane. 2011. No apparent genetic bottleneck in the demographically declining European eel using molecular genetics and forward-time simulations. Conserv. Genet. 12: 813-825.

Pujolar, J. M., I. A. M. Marino, M. Milan, A. Coppe, G. E. Maes, F. Capoccioni, E. Ciccotti, L. Bervoets, A. Covaci, C. Belpaire et al. 2012. Surviving in a toxic world: transcriptomics and gene expression profiling in response to environmentral pollution in the critically endangered European eel. BMC Genomics 13: 507.

Pujolar, J. M., M. W. Jacobsen, J. Frydenberg, T. D. Als, P. F. Larsen, G. E. Maes, L. Zane, J. B. Jian, L. Cheng, and M. M. Hansen. 2013a. A resource of genome-wide single nucleotide polymorphisms generated by RAD tag sequencing in the critically endangered European eel. Mol. Ecol. Res. 13: 706-714.

Pujolar, J. M., M. Milan, I. A. M. Marino, F. Capoccioni, E. Ciccotti, C. Belpaire, A. Covaci, G. Malarvannan, T. Patarnello, L. Bargelloni et al. 2013b. Detecting genome-wide transcription profiles associated with high pollution burden in the critically endangered European eel. Aquat. Toxicol. 132: 157-164.

Pujolar, J. M., M. W. Jacobsen, T. D. Als, J. Frydenberg, K. Munch, B. Jonsson, J. B. Jian, L. Cheng, G. E. Maes, L. Bernatchez et al. 2014a. Genome-wide single-generation signatures of local selection in the panmictic European eel. Mol. Ecol. 23: 2514-2528.

Pujolar, J. M., M. W. Jacobsen, T. D. Als, J. Frydenber, E. Magnussen, B. Jonsson, X. Jiang, L. Cheng, D. Bekkevold, G. E. Maes et al. 2014b. Assessing patterns of hybridizarion between North Atlantic eels using diagnostic single nucleotide polymorphisms. Heredity 112: 627-637.

Puritz, J. B., C. M. Hollenbeck, and J. R Gold. 2014. dDocent: a RADseq, variant-calling pipeline designed for population genomics of non-model organisms. PeerJ 2: e431.

Radwan, J., and W. Babik. 2012. The genomics of adaptation. Proc. $R$. Soc. B Biol. Sci. 279: 5024-5028.

Rasmussen, M., Y. Li, S. Lindgreen, J. S. Pedersen, A. Albrechtsen, I. Moltke, M. Metspalu, E. Metspalu, T. Kivisild, R. Gupta et al. 2010. Ancient human genome sequence of an extinct Palaeo-Eskimo. Nature 463: 757-762.

Reiss, H., G. Hoarau, M. Dickey-Collas, and W. J. Wolff. 2009. Genetic population structure of marine fish: mismatch between biological and fisheries management units. Fish Fish. 10: 361-395.

Rizzi, E., M. Lari, E. Gigli, G. De Bellis, and D. Caramelli. 2012. Ancient DNA studies: new perspectives on old samples. Genet. Sel. Evol. 44: 21.

Roberge, C., S. Einum, H. Guderley, and L. Bernatchez. 2006. Rapid parallel evolutionary changes of gene transcription profiles in farmed Atlantic salmon. Mol. Ecol. 16: 9-20.

Roberts, S. B., L. Hauser, L. W. Seeb, J. E. Seeb. 2012. Development of genomic resources for Pacific herring through targeted transcriptome pyrosequencing. PLoS One 7: e30908.

Roques, S., J. M. Sevigny, and L. Bernatchez. 2001. Evidence for broadscale introgressive hybridization between two redfish (genus $\mathrm{Se}$ bastes) in the North-west Atlantic: a rare marine example. Mol. Ecol. 10: $149-165$.

Rowe, K. C., S. Singhal, M. D. Macmanes, J. F. Ayroles, T. L. Morelli, E. M. Rubidge, K. Bi, and C. C. Moritz. 2011. Museum genomics: low-cost and high-accuracy genetic data from historical specimens. Mol. Ecol. Res. 11: 1082-1092.
Sarrapoulou, E., and J. M. Fernandes. 2011. Comparative genomics in teleost species: knowledge transfer by linking the genomes of model and non-model fish species. Comp. Biochem. Physiol. D Genomics Proteomics 6: 92-102.

Schielzeth, H., and A. Husby. 2014. Challenges and prospects in genome-wide quantitative trait loci mapping of standing genetic variation in natural populations. Ann. N Y Acad. Sci. 1320: 35-57.

Schindler, D. E., R. Hilborn, B. Chasco, C. P. Boatright, T. P. Quinn, L. A. Rogers, and M. S. Webster. 2010. Population diversity and the portfolio effect in an exploited species. Nature 465: 609-612.

Schoener, T. W. 2011. The newest synthesis: understanding the interplay of evolutionary and ecological dynamics. Science 331: 426.

Schunter, C., J. C. Garza, E. Macpherson, and M. Pascual. 2014. SNP development from RNA-seq data in a nonmodel fish: how many individuals are needed for accurate allele frequency prediction? Mol. Ecol. Resour. 14: 157-165.

Seehausen, O., R. K. Butlin, I. Keller, C. E. Wagner, J. W. Boughman, P. A. Hohenlohe, C. L. Peichel, and G. P. Saetre. 2013. Genomics and the origin of species. Nat. Rev. Genet. 5: 176-192.

Shapiro, M. D., M. E. Marks, C. L. Pelchel, B. K. Blackman, K. S. Nereng, B. Jónsson, D. Schluter, and D. M. Kingsley. 2004. Genetic and developmental basis of evolutionary pelvic reduction in threespine sticklebacks. Nature 428: 717-723.

Slate, J. 2005. Molecular evolution of the sheep prion protein gene. Proc. Biol. Sci. 272: 2371-2377.

Slatkin, M. 2008. Linkage disequilibrium: understanding the evolutionary past and mapping the medical future. Nat. Rev. Genet. 9: 477-485.

Smith, S., L. Bernatchez, and L. B. Beheregaray. 2013. RNA-seq analysis reveals extensive transcriptional plasticity to temperature stress in a freshwater species. BMC Genomics 14: 375.

Sørensen, J. G., T. N. Kristensen, and V. Loeschcke. 2003. The evolutionary and ecological role of heat shock proteins. Ecol. Lett. 6: 1025-1037.

Staats, M., R. H. J. Erkens, B. van de Vossenberg, J. J. Wieringa, K. Kraaijeveld, B. Stielow, J. Geml, J. E. Richardson, and F. T. Baker. 2013. Genomic treasure troves: complete genome sequencing of herbarium and insect museum specimens. PLoS One 8: e69189.

Stapley, J., J. Reger, P. G. D. Feulner, C. Smadja, J. Galindo, R. Ekblom, C. Bennison, A. D. Ball, A. P. Beckerman, and J. Slate. 2010. Adaptation genomics: the next generation. Trends Ecol. Evol. 12:705-712.

Star, B., A. J. Nederbragt, S. Jentoft, U. Grimholt, M. Malmstrøm, T. F. Gregers, T. B. Rounge, J. Paulsen, M. H. Solbakken, A. Sharma et al. 2011. The genome sequence of Atlantic cod reveals a unique immune system. Nature 477: 7-10.

Stinchcombe, J. R., and H. E. Hoekstra. 2008. Combining population genomics and quantitative genetics: finding the genes underlying ecologically important traits. Heredity 100: $158-170$.

Therkildsen, N. O., E. E. Nielsen, D. P. Swain, and J. S. Pedersen. 2010. Large effective population size and temporal genetic stability in Atlantic cod (Gadus morhua) in the southern Gulf of St. Lawrence. Can. J. Fish. Aquat. Sci. 67: 1585-1595.

Therkildsen, N. O., J. Hemmer-Hansen, R. B. Hedeholm, M. S. Wisz, C. Pampoulie, D. Meldrup, S. Bonanomi, A. Retzel, S. M. Olsen, and E. E. Nielsen. 2013a. Spatiotemporal SNP analysis reveals pronounced biocomplexity at the northern range margin of Atlantic cod Gadus morhua. Evol. Appl. 6: 690-705.

Therkildsen, N. O., J. Hemmer-Hansen, T. D. Als, D. P. Swain, M. J. Morgan, E. A. Trippel, S. R. Palumbi, D. Meldrup, and E. E. Nielsen. 2013b. Microevolution in time and space: SNP analysis of historical DNA reveals dynamic signatures of selection in Atlantic cod. Mol. Ecol. 22: 2424-2440. 
Toonen, R. J., J. B. Puritz, Z. H. Forsman, J. L. Whitney, I. Fernandez-Silva, K. R. Andrews, and C. E. Bird. 2013. ezRAD: a simplified method for genomic genotyping in non-model organisms. PeerJ 1: e203.

Ulrik, M. G., J. M. Pujolar, A. L. Ferchaud, M. W. Jacobsen, T. D. Als, P. A. Gagnaire, J. Frydenberg, P. K. Bøcher, B. Jonsson, L. Bernatchez, and M. M. Hansen. 2014. Do North Atlantic eels show parallel patterns of spatially varying selection? BMC Evol. Biol. 14: 138.

Vähä, J. P., and C. R. Primmer. 2006. Efficiency of model-based Bayesian methods for detecting hybrid individuals under different hybridization scenarions and with different numbers of loci. Mol. Ecol. 15: $63-72$.

Vasemägi, A., and C. R. Primmer. 2005. Challenges for identifying functionally important genetic variation: the promise of combining complementary research strategies. Mol. Ecol. 14: 3623-3642.

Via, S. 2009. Natural selection in action during speciation. Proc. Natl. Acad. Sci. USA 106: 9939-9946.

Voskoboynik, A., N. F. Neff, D. Sahoo, A. M. Newman, D. Pushkarev, W. Koh, B. Passarelli, H. C. Fan, G. L. Mantalas, K. J. Palmeri et al. 2013. The genome sequence of the colonial chordate, Botryllus schlosseri. eLife 2: e00569.

Wandeler, P., P. E. A. Hoeck, and L. F. Keller. 2007. Back to the future: museum specimens in population genetics. Trends Ecol. Evol. 22: $634-642$.

Wang, Z., M. Gerstein, and M. Snyder. 2009. RNA-Seq: a revolutionary tool for transcriptomics. Nat. Rev. Genet. 10: 57-63.

Waples, R. S. 1998. Separating the wheat from the chaff: patterns of genetic differentiation in high gene flow species. J. Hered. 89: 438450.

Ward, R. D., M. Woodwark, and D. O. F. Skibinski. 1994. A comparison of genetic diversity levels in marine, freshwater, and anadromous fishes. J. Fish Biol. 44: 213-232.

Weir, B. S., and C. C. Cockerham. 1984. Estimating F-statistics for the analysis of population structure. Evolution 38: 1358-1370.

Whitehead, A., and D. L. Crawford. 2006. Variation within and among species in gene expression: raw material for evolution. Mol. Ecol. 15: 1197-2011.

Wirth, T., and L. Bernatchez. 2003. Decline of Atlantic eels: a fatal synergy? Proc. R. Soc. B Biol. Sci. 270: 681-688.

Wooton, R. J. 1999. Ecology of teleost fishes, 2nd ed. Kluwer Academic Publishers, Dordrecht, the Netherlands. 386 pp.

Wray, G. A. 2013. Genomics and the evolution of phenotypic traits. Anпu. Rev. Ecol. Evol. Syst. 44: 55-72.

Wu, C. I. 2001. The genic view of the process of speciation. J. Evol. Biol. 14: 851-865.

Yeaman, S., and S. P. Otto. 2011. Establishment and maintenance of adaptive genetic divergence under migration, selection and drift. Evolution 65: 2123-2129.

Yeaman, S., and J. C. Whitlock. 2011. The genetic architecture of adaptation under migration-selection balance. Evolution 65: 18971911.

Zhang, G., X. Fang, X. Guo, L. Li, R. Luo, F. Xu, P. Yang, L. Zhang, X. Wang, H. Qi et al. 2012. The oyster genome reveals stress adaptation and complexity of shell formation. Nature 490:49-54. 